\title{
A Probe Into CLT Pedagogical Implications for English Majors in Mainland China: A Holistic Educational Paradigm*
}

\author{
WANG Hong-chang, XU Xiao-fei \\ Nanhu College, Jiaxing University, Jiaxing, China \\ ZHOU Zhen-xing \\ School of Foreign Languages, Jiaxing University, Jiaxing, China
}

\begin{abstract}
Notwithstanding the tremendous progress of foreign language teaching (FLT) and foreign language education (FLE) in Mainland China, there still remain large-scale margins as reflective argumentation on the issue of methodology, pedagogy, and educational paradigm to probe into. Among each respective margin concerning this FLT and FLE, this paper deepens the aspects of methodological approach of communicative language teaching (CLT) and holistic educational paradigm. Furthermore, this paper elaborates the current dominant teaching status and makes discussion on the topic of harmony between English teaching and using, taking Basic English course for English majors in Mainland China as the case study.
\end{abstract}

Keywords: communicative language teaching, English majors in Mainland China, critical thinking, holistic educational paradigm, pedagogical implications

\section{Introduction}

For many decades, English is learned as a foreign language for practical utility, and the current English as a foreign language (EFL) context in Mainland China has been regarded as enhancing students' four basic English language skills of listening, speaking, reading, and writing to improve students' English proficiency, with scratchy attention paid to the cultivation of students' proficiency to think critically, to solve dilemmatic situation independently and to lead a healthy life psychologically. Tang (2016) interprets this problematic situation as the fact that "Chinese college students generally can speak out some sentences but lack in-depth ideas and practical ability to solve problems. They suffer from emotional literacy" (p. 18). Whereas, higher education in the 21 st century should highlight the importance of critical thinking and creative innovation. For the curriculum design, innovative analytic skills should be focused more attention than the acquisition of the simple and cognitive knowledge. Actually since the 1970s, the cultivation of critical thinking in higher education has been the priority of American education reform. Up to now, the research on critical thinking has been in vogue in Western countries. In our domestic nation, critical thinking has also aroused concern of Chinese scholars. Some researchers tried to decode the specific connotation of critical thinking (Tang, 2016).

\footnotetext{
* Acknowledgements: This paper is sponsored by the project "Reform on Classroom Teaching of Basic English Course on the Basis of Communicative Language Teaching".

WANG Hong-chang, lecturer, bachelor, Department of Humanities, Nanhu College, Jiaxing University. XU Xiao-fei, assistant lecturer, master, Department of Humanities, Nanhu College, Jiaxing University. ZHOU Zhen-xing, associate professor, bachelor, School of Foreign Languages, Jiaxing University.
} 
Deplorably enough, there exists an enormous gap between the employment of the fruitful findings and the actual scenario in the context of our country. In the long run, how to bridge this existing unproductive gap is the hot concern for us to tackle.

Combining the implementation of Syllabus for English Majors in Mainland China ${ }^{1}$ with the practice of talent cultivation, Wen (2014), as the steering pioneer of English field in Mainland China, points out that the goal of cultivating talents with mixed abilities by laying the equal emphases on knowledge of related specialties with English skills and English knowledge weakens the subject characteristic of English majors. According to the summary from the lesson taught by Syllabus for English Majors, the goal of cultivating talents should regain the humanistic characteristic as its special quality, regarding English linguistics, literature, and culture as the fundamental elements.

At present, the national document for English majors is in the process of completion by the Ministry of Education. National Standards of Teaching Quality for Undergraduate English Majors ${ }^{2}$ (NSTQUEM) will provide effective guarantees and specifications for the quality teaching of English programmes in Mainland China. In details, this newly-launched document introduces the necessity, feasibility, and application of NSTQUEM. It further probes into the innovative development of English majors under the direction of the national standards (Zhong, 2015). NSTQUEM will play a crucial role as the normative and instructive document for English majors. NSTQUEM goes further step of promoting humanism within English talents, meanwhile, NSTQUEM takes literacy training as the dominate means to cultivate humanistic personality of talents in English majors. NSTQUEM emphasizes that we should not only attach importance to foster English professionals of cross-cultural communicative competence and sustainable study ability but embody the cultivation of creativity, practical ability, and critical thinking competence. To some extent, this document redefined the definition for English majors as the social science of acquisition and research of English linguistics, English literature, and English social culture. Peng (2016) interprets this document edges quality in a much more prominent position, and endows quality with refreshing contents, including social responsibility, cooperation spirit, humanism attainment, and international horizon.

\section{Stereotype About Basic English Course and the Anticipated Scenario}

It is universally acknowledged that Basic English course is the most important ingredient for English majors; it has been stipulated as the compulsive course by the board of most teaching syllabus committee in Mainland China. To some degree, Basic English course is orientated as the core professional one, whereas, the present status of this course is trapped in a modifying-emergency quandary.

\section{The Parallelismized Weight on Basic Skills and Linguistic Acquirization as Well as Humanistic Boosting}

Concerning the main content and purpose of this course, the majorities of administrators, educators, and researchers in our nation have been taking the actual concept for granted that this course plays a fundamental role for the further expansion in English, thereby laying parallel emphasis on all aspects of the intended target is formed unanimously. Wang (2014) divides the detailed content of this course into three segments as linguistic knowledge, basic skill, and humanistic literary. Obviously, the importance of reinforcing students'

\footnotetext{
${ }^{1}$ It was formulated by English Group of Foreign Language Majors Teaching Steering Committee of Higher Education. (2000). Beijing: Foreign Language Teaching and Research Press.

${ }^{2}$ It composes of three related undergraduate majors: English major (Specialty Code 050201), Translation major (Specialty Code 050261), and Business English major (Specialty Code 050262).
} 
basic language skills and boosting their humanistic qualities is highlighted, but molding adult language acquirers' moral sentiment for quality-oriented education actually outweighs the other aspects. Comparing the similar status of that with India, we can find out that it is the global puzzle in countries teaching English as a foreign language. Currently, a majority of students enter the college and receive education with the notion that they are learning, not for knowledge but for employment (Daisy, 2012). It is not unusual that some students can speak fluently with good pronunciation and perfect sentences but lack some profound and logical thoughts to infuse idea into their statement. In a certain sense, practice of the four basic skills is inevitable in FLT, but students should not be treated as passive message receivers who absorb what teachers inculcate to them without any individualized consideration. Contemporarily, Mainland China is stepping into the new millennium; examination-oriented educational system and merely-employment of English basic skills are being challenged by the in-depth talent concept.

\section{The Prevailing Methodological Pedagogy and Paradigm Employed in This Course}

Corresponding to learning of this course, teaching is an indispensable aspect. Originally, the teaching method concerning English has been taken as being monotonous, which stems from various factual situations in Mainland China. Hitherto many efforts have been made to multiply methodological pedagogy and paradigm in our domestic English teaching, including methodological teaching reform in Basic English course. Multiple teaching methods have been exploited and applied in this course all these days (Zhang, 2011; Zhu, 2013; Wang, 2014). The prevailing methodological pedagogy and paradigm initiated and applied can be categorized as follows: (1) to employ the combination of various experimental teaching methods, including discussion mode, demonstration mode, competition mode, enlightenment mode, etc.; (2) to create imitative virtual scenario for students for the dominate intention to attract students' concentration on the factual employing requirements. Creating such scenario is a tremendous stride into the diverse methodological pedagogy in this course; and (3) positive consideration in teaching paradigm is undergoing the process of being adopted. Large scales of research findings and data have already revealed the disadvantages of cramming syst. Traditional teacher-dominant classroom teaching mode usually leads to critical thinking absence, and this kind of absence has a negative effect on the promotion of students' capability to detect, deliberate, and solve problems (as cited in Zhu, 2013). Gradually, abundant newly-created paradigms and methodologies which emphasize interaction and bilingual centers in class are adopted.

\section{The Global Teaching Issue on CLT and Its Status in Mainland China}

Communicative approach is also named as Communicative Language Teaching (CLT). CLT originated from the late 1960s or earlier. It derived from a language theory which regards language as communication.

After that, CLT has been widely implemented since 1990s. Since the inception of CLT, it has served as a major source of influence on language teaching practice around the world. According to Daisy (2012), in India today the history of English language teaching has seen the rise and fall of various language teaching approaches and linguists have been trying to develop more and more innovative methods. ${ }^{3}$ Among all these approaches, CLT is the latest approach and it has influenced language teaching practice around the world. CLT is an approach to the teaching of second and foreign languages which emphasizes interaction as both the means and the ultimate goal of learning a language. By contrasting the principle characteristics of these major

${ }^{3}$ Daisy's list of Grammar Translation Method, Direct Method, Situational Language Teaching (Audiolingualism in US), etc. 
approaches, Daisy categorizes it as a comprehensive approach. The ultimate goal of CLT is to form communicative competence which is different from grammatical competence. To attain this goal, a variety of activities/tasks are carried out in a CLT classroom, including role-play, interviews, information gap, games, language exchange, survey, pair-work, and learning by teaching. The comprehensiveness of this approach makes it suitable for Basic English course for English majors.

On being aware of the deficiency that traditional grammar-translation method or audio-lingual method is more than incompetent in developing learners' communicative competence, English language teachers and researchers in Mainland China started to introduce CLT into EFL classroom teaching of all levels in the early 1980s, however, the adoption of this approach has not yielded fruitful result. The unsatisfactory achievement results from two aspects mainly, on the one hand, large majorities of students prefer traditional classroom teaching method and have a negative attitude towards the communicative-centered activities; on the other hand, most teachers feel frustrated with CLT, both partially due to students' negative response and their own lack of training. In general, the teaching-learning environment should be improved, at the same time, modified methodological pedagogy and paradigm concerning this approach and should be coined in Mainland China context.

\section{Correlation Between Holistic Education and FLE in Mainland China}

Currently, the main emphasis in education lies in acquiring large amounts of information, passing examinations and securing qualifications for future employment (Kaliannan \& Chandran, 2010). Whereas, a nation's essential empowerment in the world rely on the creation of sounded-character talents to large extent. To foster character building in academic excellence in higher education is raised by some scholars. Unfortunately, "many behavioral problems in society are vividly mirrored in schools, through bullying, drug abuse, theft and vandalism and scores of criminal acts" (Kaliannan \& Chandran, 2010, p. 802). The deplorable decadency in integrated character and crisis in fundamental values are consistently revealed by educators, thus the concept of holistic educational paradigm is spotlighted in teaching including EFL teaching throughout the world. Holistic education encompasses a wide range of philosophical orientations and pedagogical practices (Sirous, Ebrahim, Hasan, \& Mohmmd, 2012). This educational paradigm takes study as a process of growth and continual self-improvement, and learners is regarded as a "whole being", focusing on "wholeness". Kaliannan and Chandran (2010) named this identical programme as "Education in Human Values" (EHV). Because of the huge pressure of being successful academically, the jewels of childhood such as imagination and creativity are being swept aside from elementary school (Kaliannan \& Chandran, 2010, p. 803). holistic educational paradigm which nurtures self-confidence, integrity, love, and other moral values is required to be implemented as supplement during higher education stages (Jumsai, 2005) distinguishes the difference between worldly education and educare. According to his interpretation, education will equip a person with knowledge that will enable him/her to earn a living. However, "Educare" will bring out the latent human values from within and will transform the person into one with character. Education is related to educating the head whereas educare is related to education of the Heart (as cited in Kaliannan \& Chandran, 2010). The general opinion is that holistic education is concerned with life experience, not with narrowly defined "basic skills" (Sirous, Ebrahim, Hasan, \& Mohmmd, 2012).

Suo (2015) perceives that the foreign language education in Mainland China only focuses on the training language skills of listening, speaking, reading, and translating, neglecting the students' all-around development, 
resulted in the students' shortage of comprehensive capabilities, including creativity, critical thinking ability, collaborative ability, healthy values, and positive attitude. Therefore, Suo points out that holistic educational paradigm, as an approach of teaching, is the preferred methodological pedagogy to be applied in FLT in Mainland China. As for the integration of holistic educational paradigm and foreign language education (FLE), there is a tremendous distance to cover so far in Mainland China though this issue is becoming increasingly systematical.

\section{An Interpretation of a Sample Lesson as Poem in the Guidance of the Approach and Paradigm}

In accordance with the successful employment of CLT in combination with holistic educational paradigm, teachers, as the facilitators, should muster their role as change agents above all. The characteristics can be categorized as four general aspects of lifelong learning, mastery, entrepreneurship, and collaboration (Van der Heijden, Geldens, Beijaard, \& Popeijus, 2015). I cite the following famous but unknown poem named The Noble Nature by Ben Johnson as a sample lesson:

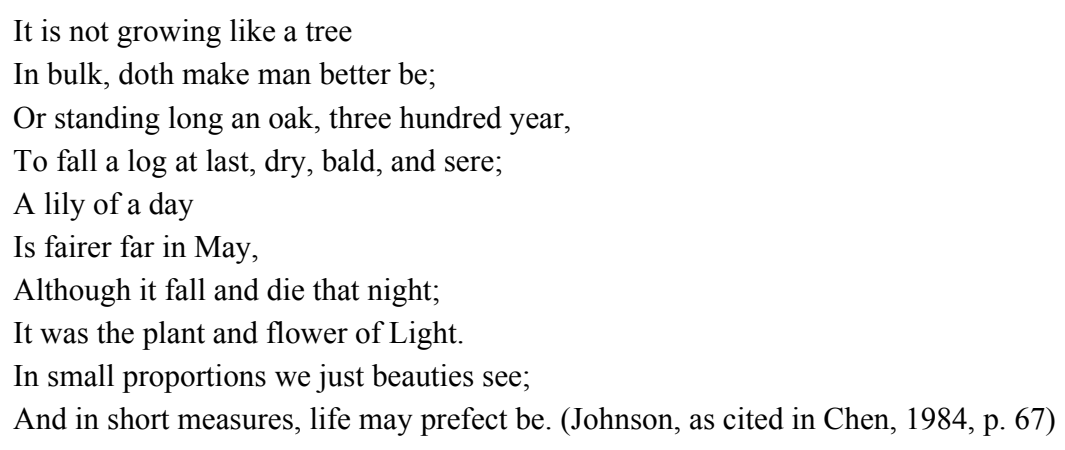

Concerning methodological pedagogy of CLT approach, an elegy to mourn for the intimate, this poem can be probed by means of interpreting, explaining, analyzing, inferring, evaluating discussing, and negotiating for the purpose of cultivating critical thinking and accelerating communicative competence. According to Breen and Candlin (1980), teachers in CLT class play two roles: Firstly, they should foster the communication and connection among all students in the classroom and provide various activities; and secondly to play the role of an independent participant within the communication-in-classroom group (as cited in Liu, 2015). On the aspect of holistic educational paradigm, the comparison and analogy between lily and friend, the wholeness of human being can be inserted by expanding the general characteristic: being eager to learn and reflective of lifelong learning, giving guidance, being accessible, positive, committed, trustful, and self-assured of mastery, being innovative and feeling responsible of entrepreneurship, and being collegial of collaboration (Van der Heijden et al., 2015). Besides, language is the vehicle of thought; sophisticated skills of expressing one's profound thoughts are the symbol of the specific individual's wholeness. In order to trigger reflective ponderness, more "open or semi-structured questions" instead of "closed questions" should occur. Holistic education suggests promoting a more balanced development of - and cultivating the relationship among - the different aspects of the individual (intellectual, physical, spiritual, emotional, social, and aesthetic), and the relationships between the individual and other people, the individual and nature, the inner-self and external. Holistic education enriches the mind, warms the heart, and awakens the spirit of learners. Generally speaking, holistic educational paradigm involves world, emotion, reason, and different forms of knowing into the wholeness of human being, it seeks an 
education that is rooted in the fundamental realities of nature and existence (Sirous, Ebrahim, Hasan, \& Mohmmd, 2012).

\section{Pedagogical Implications and Conclusion}

FLE should go beyond the conveyance of knowledge and the training of linguistic skills to students. Holistic educational paradigm is compatible with both global education and environmental education, which emphasizes the principles of interdependence and connectedness. Combining CLT approach with holistic educational paradigm is proved to be a category of prosperous methodological pedagogy. Whereas, the employment of this creative synthesis should be modified according to our domestic FLT context. Education lays emphasis on the importance of social and cultural context. Meanwhile, different countries in the globe "are extremely complex and differentiated both politically and historically. Their educational systems are two fundamentally different approaches to teaching and learning" (Ranjani, 2015, p. 244). Consequently, blending East and West for holistic educational paradigm to cater for different countries is not unnecessary for teachers. As for the adjustment of the original universal form of CLT and holistic education, in-depth assumption and initiation have been elaborately illustrated by some researchers in Mainland China. According to the argumentation, this synthesized approach should be embodied by utilizing more other approaches of the traditional teaching and context approach, and this modification is named as an eclectic model (Xiao, 2009). To our huge relief, policies advocating for pedagogy, methodology, and educational paradigm have been undergoing prosperously by authorities in Mainland China.

\section{References}

Breen, M., \& Candlin, C. N. (1980). The essentials of a communicative curriculum in language teaching. Applied Linguistics, 2 , 89-112.

Chen, J. (1984). Selected reading in English literature. Beijing: Commercial Press.

Daisy. (2012). Communicative language teaching-A comprehensive approach to English language teaching. Language in India, 12(2), 249-265.

Kaliannan, M., \& Chandran, S. D. (2010). Education in human values (EHV): Alternative approach for a holistic teaching. Educational Research and Reviews, 5(12), 802-807.

Kirkpatrick, R., \& Ghaemi, H. (2011). Beyond the communicative approach in language teaching. Modern Journal of Language Teaching Methods (MJLTM), 1(3), 143-149.

Liu, S. (2015). Reflections on communicative language teaching and its application in China. Theory and Practice in Language Studies, 5(5), 1047-1052.

Peng, Q. L. (2016). On the characteristic of National Standards of Teaching Quality for Undergraduate English majors and the relationship with different universities' standards. Foreign Language Teaching and Research, 48(1), 109-115.

Ranjani, B. I. (2015). Blending east and west for holistic education. Educational Research and Reviews, 10(3), $244-248$.

Sirous, M., Ebrahim, J., Hasan, A. N., \& Mohmmd, J. L. (2012). Holistic education: An approach for 21 century. International Education Studies, 5(3), 178-186.

Suo, J. (2015). The application of holistic education in the foreign language education. International Journal of Modern Education Forum, 4(1), 1-3.

Tang, L. Y. (2016). Exploration on cultivation of critical thinking in college intensive reading course. English Language Teaching, 9(3), 18-19.

Van der Heijden, H. R. M. A., Geldens, J. J. M., Beijaard, D., \& Popeijus, H. L. (2015). Characteristics of teachers as change agents. Teachers and Teaching: Theory and Practice, 21(6), 681-699.

Wang, J. N. (2014). A probe into reform on Basic English course construction of English major. Journal of Changchun University, 24(6), 863-864.

Wang, Z. L., \& Li, F. N. (1995). Selected reading in British literary classics. Beijing: Commercial Press. 
Wen, Q. F. (2014). English-based BA programmes with multiple concentrations: Changes and suggestions. Foreign Language Teaching and Research, 46(1), 118-126.

Xiao, L. X. (2009). A new paradigm of teaching English in China: An eclectic model. Asian EFL Journal, 11(1), $271-291$.

Zhang, H. X. (2011). Primary probe into the teaching mode of Basic English course. The Border Economy and Culture, 88(4), 98-99.

Zhong, W. H. (2015). Innovative development of English majors under the guidance of National Standards of Teaching Quality for Undergraduate English Majors. Foreign Language World, 3, 2-6.

Zhu, J. J. (2013). Cultivation of critical thinking in the teaching of Basic English course. Journal of Yangtze University (Social Sciences), 36(3), 164-165. 